\title{
Apparent synergism between amino donors for CTP synthesis in Chinese hamster fibroblasts
}

John D. McLaren and Ernest H. Y. Chu

Department of Human Genetics, University of Michigan Medical School, Ann Arbor, MI 48109, U.S.A.

\section{Summary}

The synergistic effects of potential a mino donors were studied in the assay of CTP synthetase in extracts of Chinese hamster fibroblasts. We found that L-glutamine was not effective as the sole amino donor, but combinations of L-glutamine with $\mathrm{NH}_{4} \mathrm{HCO}_{3}$, L-arginine or potassium phosphate did result in the conversion of UTP to CTP. L-arginine or potassium phosphate were also not effective when used alone, and $\mathrm{NH}_{4} \mathrm{HCO}_{3}$ was only slightly effective. Our studies demonstrate that the individual synergistic combinations were not additive; multiple combinations of components decreased rather than increased the formation of CTP.

The synergistic combinations of L-glutamine with either $\mathrm{NH}_{4} \mathrm{HCO}_{3}$ or L-arginine had an absolute requirement for ATP; when ATP and PEP were absent no conversion of UTP to CTP occurred. The presence of GTP in a reaction mixture slightly increased the formation of CTP when L-glutamine and $\mathrm{NH}_{4} \mathrm{HCO}_{3}$ were used and substantially increased CTP formation when L-glutamine and L-arginine were used. De novo CTP synthesis was greatly reduced when nonradioactive CTP was added to an assay mixture, suggesting feedback inhibition.

A TLC procedure has been developed that allows for the direct separation of UTP and CTP without requiring prior conversion to the mononucleotide or nucleoside level.

\begin{abstract}
Abbreviations
$\beta$-ME, $\beta$-mercaptoethanol; PEI, polyethyleneimine; PEP, phosphoenolpyruvate; TLC, thin layer chromatography.
\end{abstract}

\section{Introduction}

Cytidine 5'-Triphosphate synthetase(CTPS, E.C. 6.3.4.2) catalyzes the irreversible reaction: UTP + glutamine $\left(\right.$ or $\left.\mathrm{NH}_{3}\right)+\underset{\mathrm{GTP}}{\stackrel{\mathrm{ATP}}{\mathrm{MTg}}{ }^{2+}} \mathrm{CTP}+$ glumatic acid + ADP + Pi. When glutamine is used as the amino donor, GTP is an allosteric effector; when $\mathrm{NH}_{3}$ is the amino donor, GTP is ineffective (1). CTPS enzyme assays have been published utilizing a plethora of tissues and cells (2-11). CTPS enzyme assays depend on the ability to detect the conversion of UTP to CTP. There are basically two types of assay procedures: 1) a spectrophotometric procedure that detects the accumulation of CTP (6, 12 ), and 2) radioisotopic procedures that detect the conversion of the radioactive substrate UTP to the product CTP. These radioisotopic methods either: a) require acid hydrolysis of UTP and CTP to the mononucleotide level, followed by chromatography $(2,3,5,6,8,10,11,13,14)$, b) require enzymatic 
conversion of UTP and CTP to the nucleoside level, followed by chromatography (7), or c) directly separate UTP and CTP by chromatography $(3,4,8$, 9 ). The radioisotopic assay procedures are more sensitive than the spectrophotometric procedure, allowing for a reduction in the total assay volume. A procedure that allows for the direct chromatographic separation of UTP and CTP has the advantages of eliminating extra manipulation of the samples, as well as allowing multiple samples to be run on a single TLC sheet. In this paper we describe an improved TLC procedure that can directly separate UTP and CTP to a greater extent than was possible using the published procedures. Our method has the additional advantage that CTP migrates with a greater Rf than UTP; this minimizes the chance that the minor component, CTP, will be contaminated by streaking of the major component UTP.

In all of the CTPS assay procedures we were aware of, the amino donor could be either L-glutamine or $\mathrm{NH}_{3}$. However, our initial CTPS assays of Chinese hamster lung cell extracts, using L-glutamine, failed to detect a conversion of UTP to CTP. Our observation that the addition of a source of $\mathrm{NH}_{3}\left(\mathrm{NH}_{4} \mathrm{HCO}_{3}\right)$ to the assay mix already containing L-glutamine resulted in the formation of CTP was later discovered to be an example of apparent synergism between amino donors, a phenomenon hitherto unreported. We further demonstrated that the synergistic combination of L-glutamine and L-arginine, or to a lesser extent L-glutamine and inorganic phosphate, also resulted in the conversion of UTP to CTP.

\section{Materials and methods}

\section{Materials}

[2-14C] UTP, tetrasodium salt $(46.8 \mathrm{mCi} / \mathrm{mmol})$ was purchased from New England Nuclear Corp. (Boston, Massachusetts). Polyethyleneimine (PEI) cellulose thin layer plates (Polygram Cel $300 \mathrm{PEI}$ ) were purchased from Brinkmann Instruments, Inc. (Westbury, New York). The biochemicals were purchased from Sigma Chemical Co. (St. Louis, Missouri); other chemicals were of reagent grade and were purchased from various sources.

\section{Conditioning of PEI thin layer sheets}

Prior to use in the CTPS assay, the PEI thin layer sheets were developed overnight in $10 \% \mathrm{NaCl}$; this step washed a yellowish material to the top of the thin layer sheet. The thin layer sheets were immediately washed with running distilled water for about 1 minute; this step is very important, as the distilled water washed off the $\mathrm{NaCl}$ solution and most of the yellowish material at the upper edge of the plate. Insufficient washing with distilled water will leave $\mathrm{NaCl}$ on the plate and will interfere with the subsequent use of the plate in the CTPS assay. The washed plates were then dried in a hood and stored in a box in a refrigerator.

\section{Thin layer chromatography}

A $20 \times 20 \mathrm{~cm}$ conditioned PEI cellulose TLC sheet was lightly marked with a pencil prior to spotting, to denote the sample lanes. A horizontal line was drawn $2 \mathrm{~cm}$ from the 'bottom' of the TLC sheet; the 'bottom' was that side of the TLC sheet that was placed in $10 \% \mathrm{NaCl}$ as part of the conditioning process. Six sample lanes of $1.5 \mathrm{~cm}$ width could be marked along the line with ample spacing to prevent overlap. Twenty $\mu \mathrm{l}$ of a mixture of nonradioactive UTP, CTP and UDP at a concentration of $3.3 \mathrm{mM}$ each was spotted and dried on each sample lane prior to spotting the aliquots from the reaction mixture. Non-radioactive UTP, CTP and UDP markers were spotted between sample lanes. After all samples had been spotted and dried on the TLC plate, the plate was developed in a rectangular glass tank using $0.5 \mathrm{~N} \mathrm{HCl}$; the TLC plate was dried overnight in a hood. The marker spots were located using short wave UV light $(254 \mathrm{~nm})$, and the areas corresponding to UTP, CTP and UDP were carefully outlined with a pencil. $\mathrm{Rf}$ values using this system are: UTP, 0.09; CTP, 0.25; and UDP, 0.51 . The UV visible bands with $R f$ values less than CTP correspond to ATP and GTP, which are components of the assay reaction mixture; the separate CTP marker will clearly indicate the area to be circled and counted as CTP. When the developed plate is observed under UV, one will see several wavy horizontal lines at $\mathrm{Rf} 0.7$ to 0.85 ; the compounds UMP, CMP, and CDP will migrate together between the wavy lines at Rf's of $0.73,0.76$ and 0.72 respectively. Four areas are cut out for 
each sample lane, corresponding to the UTP, CTP and UDP markers, as well as the area between and including the wavy lines (UMP, CMP and CDP) and each is counted separately in a liquid scintillation vial. The gross percentage of total cpm for each component, i.e. UTP, CTP etc., is calculated by dividing the $\mathrm{cpm}$ for each component by the sum of the cpm for the four areas counted.

\section{Cell culture}

A Chinese hamster cell line (V79), derived originally from the lung tissue of a male Chinese hamster, was used. The growth medium was a modified Eagle's Minimal Essential Medium supplemented with 5\% fetal calf serum. Cells were seeded at 1-2 $\times 10^{6}$ per $10 \mathrm{~cm}$ tissue culture dish and grown for two days at $37{ }^{\circ} \mathrm{C}$ in a humidified incubator supplied with $5 \% \mathrm{CO}_{2}$ in air. Cells at $\log$ phase of growth from 12-16 dishes were collected using $0.01 \%$ trypsin in phosphate-buffered saline (PBS). After two washes with PBS, cells were ready for immediate use or stored at $-70^{\circ} \mathrm{C}$.

\section{Preparation of cell extracts}

Cell pellets were mixed with $0.4-1.0 \mathrm{ml}$ of one of the following buffers: 1) $0.08 \mathrm{M}$ Tris, $\mathrm{pH} 7.4$; 2) 0.08 $\mathrm{M}$ Tris, pH 7.4, $40 \mathrm{mM}$ L-glutamine, $40 \mathrm{mM} \beta$ mercaptoethanol $(\beta$-ME); 3) $0.075 \mathrm{M}$ glycylglycine, $\mathrm{pH} 7.4,20 \mathrm{mM} \beta-\mathrm{ME}$; or 4) $0.075 \mathrm{M}$ glycylglycine, $\mathrm{pH} 7.4,20 \mathrm{mM}$ L-glutamine, $20 \mathrm{mM} \beta$-ME. Disruption of cells was accomplished by either sonication or homogenization. Sonic disruption was done by a) placing the cell suspension in a $1.5 \mathrm{ml}$ conical centrifuge tube, $b$ ) immersing the lower half of the tube in ice water, and c) sonicating the cell suspension in short bursts $(5-15 \mathrm{sec})$, followed by cooling periods, for a total sonication time of up to 1 minute. A Branson Sonifier Cell Disrupter, Model 185 , with a stepped microtip was used. Homogenization was achieved using a motor driven teflon pestle and a plexiglass holder. The cell suspension was placed in the holder and the lower half of the holder was placed in ice water; 50 strokes of the teflon pestle were used to disrupt the cells. Disrupted cell suspensions were placed in $1.5 \mathrm{ml}$ conical centrifuge tubes, and the tubes were centrifuged at $11000 \mathrm{rpm}$ (approx. $15000 \times \mathbf{g}$ ) for 15 minutes, using a Sorvall centrifuge and SS-34 rotor. The supernatants were removed and placed in new conical centrifuge tubes for storage at $-70^{\circ} \mathrm{C}$, or were subjected to an additional ultracentrifugation step. Using polycarbonate bottles made for use with the Beckman type 50 fixed angle rotor, the ultracentrifugation was carried out at $40000 \mathrm{rpm}$ (approx. $100000 \times \mathrm{g}$ ) for 60 minutes at a temperature of 5 $10^{\circ} \mathrm{C}$. The supernatants obtained were placed in $1.5 \mathrm{ml}$ conical centrifuge tubes and stored at $-70^{\circ} \mathrm{C}$.

\section{CTPS enzyme assay}

The assay of CTP synthetase is based on the conversion of ${ }^{14} \mathrm{C}$-UTP to ${ }^{14} \mathrm{C}$-CTP, followed by the separation of substrate and product(s) by PEI cellulose TLC. The reaction mixture generally contained the following components and final concentrations: glycylglycine, $\mathrm{pH} 7.4,0.075 \mathrm{M}$ or $0.105 \mathrm{M}$; ATP, $8 \mathrm{mM}$; PEP, $8 \mathrm{mM}$; GTP, $4 \mathrm{mM}$; $\mathrm{NaF}$, $10 \mathrm{mM} ; \mathrm{MgCl}_{2}, 20 \mathrm{mM} ; \beta$-ME, $20 \mathrm{mM}$ or $28 \mathrm{mM}$; UTP, $0.2 \mathrm{mM}$; and $\left[2-{ }^{14} \mathrm{C}\right] \mathrm{UTP}, 4.27 \times 10^{-5} \mathrm{M}$, $0.1 \mu \mathrm{Ci} / 50 \mu \mathrm{l}$ final assay volume. The amino donors and their final concentrations, as well as other components, are listed in the legends for each table and figure. The assays were run using $1.5 \mathrm{ml}$ conical centrifuge tubes and the final volume of the reaction mixture was $50 \mu \mathrm{l}$ ( $25 \mu \mathrm{l}$ for some experiments). All assays were performed at $37^{\circ} \mathrm{C}$ using a temperature block. The CTPS assay was initiated by adding $20 \mu \mathrm{l}$ of cell extract to give a final volume of $50 \mu \mathrm{l}$ (exceptions as noted in legends). At various times after adding the cell extract, a $5 \mu \mathrm{l}$ aliquot of the assay mixture was spotted directly on a $1.5 \mathrm{~cm}$ lane on a conditioned PEI cellulose TLC sheet and was dried with warm air from a hair dryer. After all samples had been spotted and dried on the TLC sheet, the sheet was developed in $0.5 \mathrm{~N} \mathrm{HCl}$, as indicated in the section on thin layer chromatography.

\section{Results}

\section{Amino donors in the CTPS assay}

Our initial CTPS assays of V79 Chinese hamster lung cell extracts, using L-glutamine as the amino donor, failed to detect any conversion of UTP to CTP. Two approaches were used to pinpoint the problem with the assay. The first approach in- 
volved the use of another potential amino donor, $\mathrm{NH}_{4} \mathrm{HCO}_{3}$, in combination with L-glutamine. The second approach was aimed at reducing possible breakdown of ATP and GTP during the course of the assay by adding inorganic phosphate to the reaction mixture; Table 1 shows the results of these experiments. L-glutamine, when used alone as the amino donor, is clearly not effective, while the combination of L-glutamine and $\mathrm{NH}_{4} \mathrm{HCO}_{3}$ results in substantial conversion of UTP to CTP. The combination of L-glutamine and potassium phosphate also results in the production of CTP, but at a lower level. Table $1 \mathrm{~A}$ shows that the combination of L-glutamine, $\mathrm{NH}_{4} \mathrm{HCO}_{3}$ and potassium phosphate results in a level of CTP production that is intermediate between the two individual combinations, suggesting that the three components may be competitive in nature.

When either L-glutamine or potassium phosphate alone was present in the assay mixture, little or no CTP was formed (Table lB). When $\mathrm{NH}_{4} \mathrm{HCO}_{3}$ alone was used, some CTP was produced, but the amount was considerably less than when L-glutamine and $\mathrm{NH}_{4} \mathrm{HCO}_{3}$ were used together. Further-

Table 1. Effect of amino donors in the assay of CTPS using V79 cell extracts. For part A, the cell extract was prepared in $0.08 \mathrm{M}$

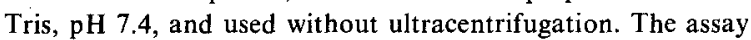
volume was $50 \mu \mathrm{l}$ total, including $20 \mu \mathrm{l}$ of cell extract. The final concentrations of components were: $0.032 \mathrm{M}$ Tris, $0.075 \mathrm{M}$ glycylglycine, pH 7.4; $8 \mathrm{mM}$ ATP; $8 \mathrm{mM}$ PEP; $4 \mathrm{mM} \mathrm{GTP;} 20 \mathrm{mM}$ $\mathrm{MgCl}_{2} ; 20 \mathrm{mM} \beta-\mathrm{ME} ; 10 \mathrm{mM} \mathrm{NaF} ; 0.2 \mathrm{mM}$ non-radioactive UTP; $4.27 \times 10^{-5} \mathrm{M}\left[2{ }^{-14} \mathrm{C}\right] \mathrm{UTP} ; 0.1 \mu \mathrm{Ci} / 50 \mu \mathrm{l}$ assay volume. Fort part $B$, the cell extract was prepared in $0.075 \mathrm{M}$ glycylglycine, $\mathrm{pH} 7.4,20 \mathrm{mM} \beta$-ME and ultracentrifuged prior to use. The final concentrations of components were: $0.105 \mathrm{M}$ glycylglycine, $\mathrm{pH} 7.4 ; 28 \mathrm{mM} \beta$-ME; others as above, excluding Tris. The rest are listed in the table.

\begin{tabular}{lcr}
\hline Amino donor(s) & \multicolumn{1}{c}{$\begin{array}{l}\text { Gross \% of total cpm } \\
\text { as CTP/3 hr } \\
\text { incubation }\end{array}$} \\
\cline { 2 - 3 } & A & B \\
\hline L-glutamine & 0.46 & 0.60 \\
L-glutamine $+\mathrm{NH}_{4} \mathrm{HCO}_{3}$ & 19.03 & 30.90 \\
L-glutamine + potassium phosphate & 9.36 & 9.55 \\
L-glutamine $+\mathrm{NH}_{4} \mathrm{HCO}_{3}+$ & & \\
$\quad$ potassium phosphate & 12.41 & \\
NH $_{4} \mathrm{HCO}_{3}$ & & 4.73 \\
Potassium phosphate & & 0.46 \\
\hline
\end{tabular}

a Final concentrations of all compounds were $20 \mathrm{mM}$; that of $\mathrm{NH}_{4} \mathrm{HCO}_{3}$ was $40 \mathrm{mM}$.
Table 2. Synergistic combinations of amino acids as amino donors in CTP synthesis. Preparation of V79 cell extract and assay conditions were the same as those detailed in Table $1 \mathrm{~B}$ except 20 $\mathrm{mM} \mathrm{L-glutamine} \mathrm{was} \mathrm{included} \mathrm{in} \mathrm{the} \mathrm{extraction} \mathrm{buffer.}$

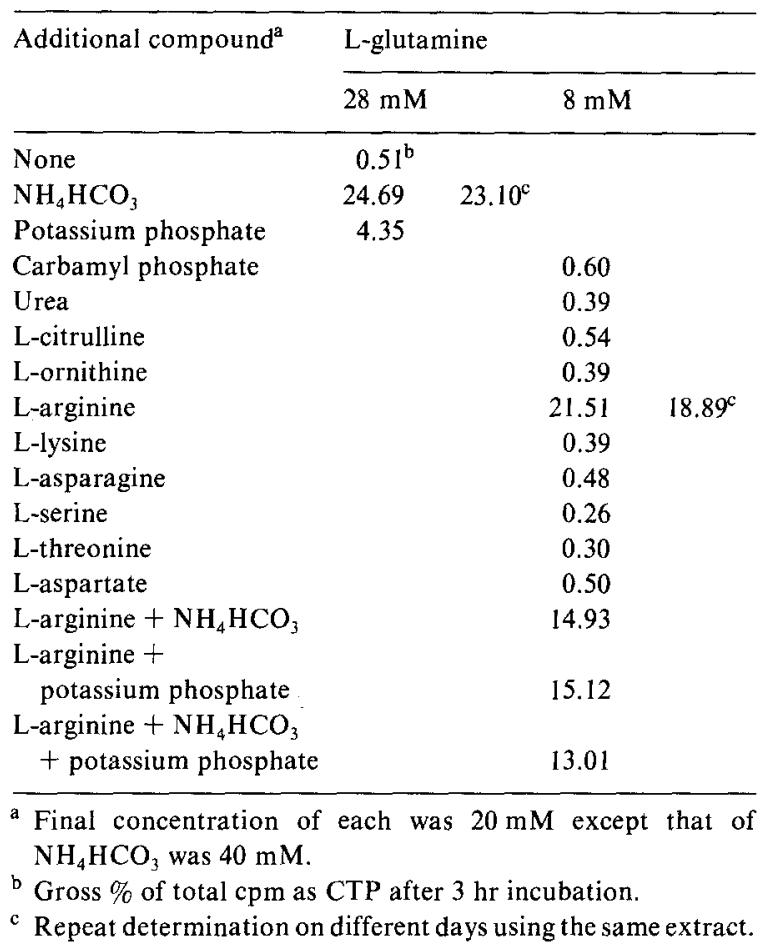

more, when L-glutamine and potassium phosphate were used together some CTP was formed. Thus, the combination of L-glutamine and $\mathrm{NH}_{4} \mathrm{HCO}_{3}$ or potassium phosphate appears to be an example of synergism in the conversion of UTP to CTP, and L-glutamine is the common and necessary component.

The possibility was tested whether other potential amino donors may also synergistically combine with L-glutamine to convert UTP to CTP. The results (Table 2) again demonstrate the synergistic combinations of L-glutamine and $\mathrm{NH}_{4} \mathrm{HCO}_{3}$ or potassium phosphate. Only L-arginine, of all the potential amino donors tested in combination with L-glutamine, can convert UTP to CTP. The greatest conversion of UTP to CTP was observed when only L-glutamine and L-arginine were in the reaction mixture as potential amino donors. The addition of $\mathrm{NH}_{4} \mathrm{HCO}_{3}$ or potassium phosphate, or both, reduces the amount of CTP formed. Again the presence of multi amino donors reduces rather than enhances the conversion of UTP to CTP, pos- 
Table 3. Similarities and differences in the effect of amino donors in assays of CTP synthetase comparing extracts of two different lines of Chinese hamster cells. Preparation of V79 cell extract and assay conditions for parts $\mathrm{A}$ and $\mathrm{B}$, performed on different days, were the same as those described in Table 1B. Preparation of $\mathrm{CHO}-\mathrm{Kl}$ cell extract and assay conditions for parts $C$ and $D$, performed on different days, were the same as those described in Table $1 \mathrm{~A}$.

\begin{tabular}{|c|c|c|c|c|}
\hline \multirow[t]{2}{*}{ Amino donor $(s)^{a}$} & \multicolumn{4}{|c|}{$\begin{array}{l}\text { Gross } \% \text { of total cpm as } \\
\text { CTP } / 3 \mathrm{hr} \text { incubation }\end{array}$} \\
\hline & A & B & $\mathrm{C}$ & $\mathrm{D}$ \\
\hline L-glutamine & \multicolumn{2}{|l|}{0.41} & 2.27 & \multirow[t]{3}{*}{2.81} \\
\hline L-arginine & \multicolumn{2}{|l|}{0.98} & 2.31 & \\
\hline L-glutamine + L-arginine & \multicolumn{2}{|l|}{32.81} & 32.08 & \\
\hline \multicolumn{2}{|l|}{ L-glutamine $+\mathrm{NH}_{4} \mathrm{HCO}_{3}$} & \multicolumn{2}{|l|}{32.55} & \multirow[t]{3}{*}{32.42} \\
\hline L-arginine $+\mathrm{NH}_{4} \mathrm{HCO}_{3}$ & & 5.67 & & \\
\hline \multicolumn{2}{|l|}{ L-arginine + potassium phosphate } & 0.76 & & \\
\hline \multicolumn{2}{|l|}{ L-glutamine + potassium phosphate } & & & 31.49 \\
\hline
\end{tabular}

a Final concentrations of all compounds were $20 \mathrm{mM}$; that of $\mathrm{NH}_{4} \mathrm{HCO}_{3}$ was $40 \mathrm{mM}$.

sibly due to competition between amino donors.

Table $3 \mathrm{~A}$ gives the results of a separate experiment showing that the conversion of UTP to CTP by the combination of L-glutamine and L-arginine appears to be a synergistic process. L-arginine plus potassium phosphate yields little or no CTP, while L-arginine plus $\mathrm{NH}_{4} \mathrm{HCO}_{3}$ results in some CTP production at a level that is considerably less than the amount of CTP produced by L-glutamine and $\mathrm{NH}_{4} \mathrm{HCO}_{3}$ (Table 3B). This suggests that the synergistic combination between L-arginine and L-glutamine is specific and unique.

Table 3 also shows the results of experiments performed using cell extracts of Chinese hamster ovary CHO K 1 cells. When L-glutamine or L-arginine was used separately as the sole amino donor, a small but measurable conversion of UTP to CTP was observed. However, when L-glutamine was combined with $\mathrm{NH}_{4} \mathrm{HCO}_{3}$, potassium phosphate or L-arginine, a substantial conversion of UTP to CTP occurred.

\section{Non-involvement of glutaminase}

Glutaminase [E.C. 3.5.1.2] hydrolyzes L-glutamine to give L-glutamate and $\mathrm{NH}_{3}$. The apparent synergism we observed between L-glutamine and $\mathrm{NH}_{4} \mathrm{HCO}_{3}$ could be explained by the possibility that the ammonia source $\left(\mathrm{NH}_{4} \mathrm{HCO}_{3}\right)$ inhibits the breakdown of L-glutamine. In the absence of ammonia, L-glutamine might be hydrolyzed, preventing CTP synthetase from converting UTP to CTP. The results of our experiments (data not shown) have ruled out this possibility. When the CTP synthetase assay contained ${ }^{3} \mathrm{H}$-UTP and ${ }^{14} \mathrm{C}$-L-glutamine, we determined if CTP was formed and if L-glutamine was hydrolyzed to L-gluta mate. When the reaction mixture contained ${ }^{12} \mathrm{C}$ and ${ }^{14} \mathrm{C} \mathrm{L}$-glutamine, but not $\mathrm{NH}_{4} \mathrm{HCO}_{3}$, we observed practically no CTP formation or hydrolysis of L-glutamine. When $\mathrm{NH}_{4} \mathrm{HCO}_{3}$ was present in addition to ${ }^{12} \mathrm{C}$ and ${ }^{14} \mathrm{C}$-L-glutamine, CTP was readily formed and a small amount of L-glutamate was also formed.

\section{Obligatory components in the CTPS assay}

The biochemical equation describing the CTPS reaction indicates that three components are required as substrates, i.e. UTP, L-glutamine or $\mathrm{NH}_{3}$, and ATP. Additionally, $\mathrm{Mg}^{2+}$ is required and GTP is an allosteric effector when L-glutamine is used. Table 4 summarizes the results of an experiment in which key components were omitted from a CTPS reaction mixture. There are two parts to the experiment: the first part uses both L-glutamine and $\mathrm{NH}_{4} \mathrm{HCO}_{3}$ as the amino donors, and the second part uses both L-glutamine and L-arginine as the amino donors. When both L-glutamine and $\mathrm{NH}_{4} \mathrm{HCO}_{3}$ were included in a complete reaction mixture containing all necessary components, substantial conversion of UTP to CTP took place. The elimination of GTP from the reaction mixture results in some reduction (about 16\%) in the production of CTP. When only ATP and PEP were eliminated, essentially no CTP was formed; this was expected because ATP is a necessary component. When only $\mathrm{NH}_{4} \mathrm{HCO}_{3}$ was eliminated, essentially no CTP was formed. We have shown earlier that the combination of L-glutamine and $\mathrm{NH}_{4} \mathrm{HCO}_{3}$ is required as amino donors, so the removal of $\mathrm{NH}_{4} \mathrm{HCO}_{3}$ from a reaction mixture prevents the formation of CTP. When the combination of L-glutamine and $\mathrm{L}$-arginine was used as amino donors in a complete reaction mixture, UTP was converted to CTP. The elimination of GTP from the reaction mixture results in a reduction (about $51 \%$ ) of CTP formation. When both ATP and PEP were omitted from an otherwise complete reaction mixture, essentially no CTP was formed. Finally, when only 
Table 4. Obligatory components in the assay of CTPS with V79 cell extracts. Preparation of cell extract was the same as those described in Table $1 \mathrm{~B}$ except $20 \mathrm{mM} \mathrm{L}$-glutamine was included in the extract buffer. The assay conditions remained the same. The concentrations of ATP, PEP and GTP were those for the complete reaction mixture; they were deleted where indicated in the table.

\begin{tabular}{|c|c|c|c|}
\hline Composition of assay mix & Amino donor(s) & $\begin{array}{l}\text { Final concentration } \\
\text { of amino donor(s), } \mathrm{mM}\end{array}$ & $\begin{array}{l}\text { Gross } \% \text { of total cpm } \\
\text { as CTP } / 3 \mathrm{hr} \text { incubation }\end{array}$ \\
\hline \multirow[t]{3}{*}{ Complete } & L-glutamine & 28 & \\
\hline & + & & 12.64 \\
\hline & $\mathrm{NH}_{4} \mathrm{HCO}_{3}$ & 40 & \\
\hline$-\mathrm{NH}_{4} \mathrm{HCO}_{3}$ & L-glutamine & 28 & 0.19 \\
\hline \multirow[t]{3}{*}{-ATP, -PEP } & L-glutamine & 28 & \\
\hline & + & & 0.29 \\
\hline & $\mathrm{NH}_{4} \mathrm{HCO}_{3}$ & 40 & \\
\hline \multirow[t]{3}{*}{$-\mathrm{GTP}$} & L-glutamine & 28 & \\
\hline & + & & 10.60 \\
\hline & $\mathrm{NH}_{4} \mathrm{HCO}_{3}$ & 40 & \\
\hline \multirow[t]{3}{*}{ Complete } & L-glutamine & 8 & \\
\hline & + & & 7.86 \\
\hline & L-arginine & 20 & \\
\hline -L-arginine & L-glutamine & 8 & 0.31 \\
\hline \multirow[t]{3}{*}{-АТP, -PEP } & L-glutamine & 8 & \\
\hline & + & & 0.17 \\
\hline & L-arginine & 20 & \\
\hline \multirow[t]{3}{*}{-GTP } & L-glutamine & 8 & \\
\hline & + & & 3.85 \\
\hline & L-arginine & 20 & \\
\hline
\end{tabular}

L-arginine was eliminated, practically no CTP was formed.

\section{Time course of the CTPS assay}

The conversion of UTP to CTP appears to proceed linearly with time until about $20-25 \%$ of the substrate UTP (initial concentration is $0.2427 \mathrm{mM}$ ) has been converted to CTP, whereupon the rate gradually decreases (Fig. 1). The decrease in CTP formation could be due to substrate depletion and/ or CTP feedback inhibition.

\section{Inhibition of CTP synthetase by CTP}

In a control experiment (not shown) using $0.2427 \mathrm{mM}$ UTP, $28 \mathrm{mM}$ L-glutamine and $40 \mathrm{mM}$ $\mathrm{NH}_{4} \mathrm{HCO}_{3}$ plus all other necessary components, $23.2 \%$ gross conversion of UTP to CTP occurred after $3 \mathrm{hr}$ of incubation. When $0.2 \mathrm{mM}$ non-radioactive CTP was added to a complete reaction mixture prior to the start of the assay, only $6.5 \%$ gross conversion of UTP to CTP per $3 \mathrm{hr}$ of incubation occurred. This is about a $72 \%$ reduction in

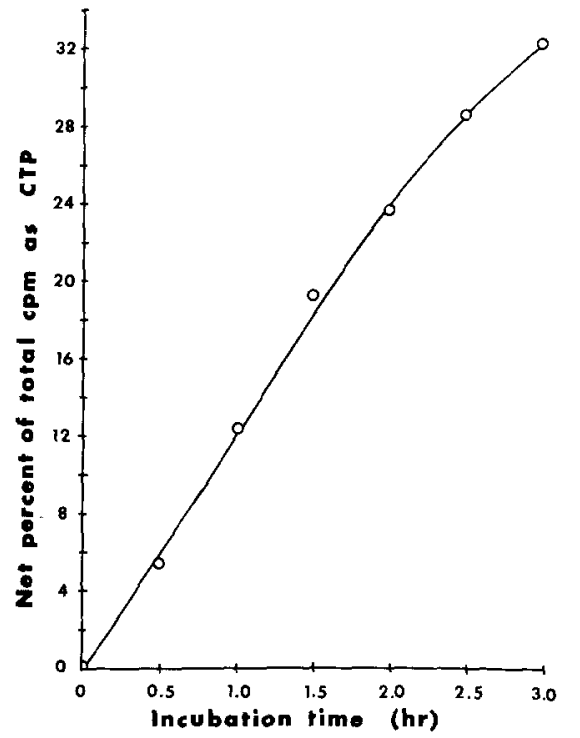

Fig. 1. Time course of the CTPS assay using V79 cell extracts. Preparation of cell extract and assay conditions were the same as those described in Table 1B. $20 \mathrm{mM} \mathrm{L}$-glutamine and $40 \mathrm{mM}$ $\mathrm{NH}_{4} \mathrm{HCO}_{3}$ were included in the reaction mixture which had a total volume of $100 \mu 1$, including $40 \mu 1$ of the cell extract. Five $\mu 1$ samples are taken at $t \sim 0^{\prime}$ (immediately after adding the cell extract), and at one-half hour intervals up to $3 \mathrm{hr}$. 


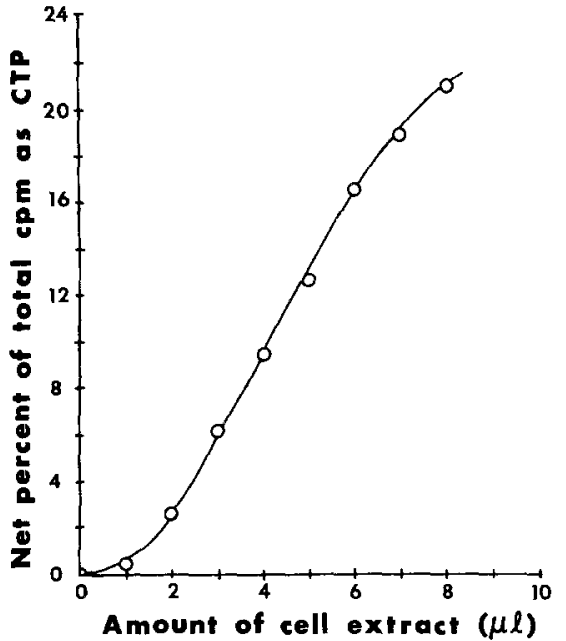

Fig. 2. Amount of CTP produced vs amount of V79 cell extract used in the CTPS assay. Preparation of cell extract and assay conditions were the same as those described in Table $1 \mathrm{~B}$ and Fig. 1 except that the total volume of the reaction mixture was $25 \mu 1$ including $0-8 \mu$ l of the cell extract. The incubations were at $37^{\circ} \mathrm{C}$ for $2 \mathrm{hr}$

CTP formation. Clearly, the decrease in the rate of CTP formation observed in the time course assay could be due to CTP feedback inhibition of the enzyme.

\section{Production of CTP as a function of the amount of extract used}

Figure 2 shows the results of an experiment in which various amounts of V79 cell extract were incubated under identical conditions and the amount of CTP formed in each assay was measured. The graph shows an initial lag phase when small amounts of extract were used, followed by a linear increase in CTP production until about $20-25 \%$ of the substrate UTP has been converted to CTP. The observation of a lag phase when the smallest amounts of cell extract were used suggests that there may be inactivation of the CTPS under these conditions.

\section{Discussion}

The use of thin layer chromatography (TLC) in the assay of CTPS has the obvious advantage that it allows multiple samples to be run at the same time.
However, the time saving advantage of TLC may be negated if preparations of the samples are required prior to chromatography; this is the case when the pyrimidine nucleotides must be acid hydrolyzed to the mononucleotide level or enzymatically converted to the corresponding nucleosides. The TLC procedure described in this communication allows for a direct separation of UTP and CTP, and the degree of separation is such that the product of the assay, CTP, migrates clearly ahead of the substrate UTP. We have found the procedure simple to perform and the results reproducible.

The observation of apparent synergism between potential a mino donors in the assay of CTP synthetase has not, to our knowledge, been previously reported. Our experiments demonstrate that several combinations of potential amino donors are effective in allowing the conversion of UTP to CTP, i.e., L-glutamine plus $\mathrm{NH}_{4} \mathrm{HCO}_{3}$, L-glutamine plus $\mathrm{L}$-arginine, and L-glutamine plus potassium phosphate. Clearly, the complete understanding of the apparent synergism will require kinetic studies devoted to the mechanism of the purified enzyme. The reason for developing the modified CTPS assay procedure and for using Chinese hamster cell extracts was a prelude to studies with Chinese hamster cell CTPS mutants isolated in this laboratory. The results on the genetic and biochemical characterization of these mutants will be presented elsewhere. However, it is possible to discuss what is currently known about the mechanism of CTPS and to suggest where our observations may fit into the scheme. Koshland and Levitzki in their excellent review (1) have detailed the mechanism of CTPS; this review provides the basis for the following discussion concerning the mechanism. The enzyme functions as a tetramer of 4 identical subunits. The initial step involves the reaction between the a mino donor L-glutamine and the CTPS to form a complex; the linkage is via a thioester bond with a cysteine molecule from the enzyme. The formation of the complex results in the liberation of ammonia. Apparently the complex can form when the enzyme is a dimer and ATP and UTP are absent. The tetramer forms in the presence of ATP and UTP. The L-glutamyl-enzyme complex then reacts with water to give the free enzyme and L-glutamic acid. The allosteric effector, GTP, apparently assists in producing a conformational change in the enzyme which specifically involves the formation of the 
L-glutamyl-enzyme complex. When ammonia is used as the amino donor instead of L-glutamine, no L-glutamyl-enzyme complex can be formed; thus GTP only has an allosteric effect when L-glutamine is the amino donor. The L-glutamine analog 6-diazo-5-oxo-L-norleucine (DON) can react with a cysteine molecule to prevent the L-glutamine reaction with the S-H group, thus inhibiting the reaction.

The exact mechanism of the subsequent steps is not precisely known, but the steps occur rapidly and are not dependent on the amino donor used. One possible mechanism would occur in the following order. When the amino donor is L-glutamine, the $\mathrm{NH}_{3}$ formed 1) reacts immediately with UTP to form an adduct, 2) this adduct then reacts with ATP to give a phosphorylated adduct of UTP plus ADP, and 3) the phosphorylated adduct of UTP eliminates phosphate to yield CTP. When L-glutamine is the amino donor the liberated $\mathrm{NH}_{3}$ reacts directly with UTP and does not interact with the solvent; this will happen only if both UTP and ATP are present. When either UTP or ATP is absent, the liberated $\mathrm{NH}_{3}$ will interact with the solution.

An analog of ATP, adenylimidodiphosphate (AMP-PNP) has been used in place of ATP to help elucidate the role played by ATP. The analog has a $-N$ - bond between the $\beta$ and $\gamma$ phosphates, $\mathrm{H}$

replacing the -0-bond. When AMP-PNP is used in place of ATP in the CTPS assay, the analog apparently occupies the same site ATP would normally occupy, but it is not used as a substrate. When all necessary components are present in the CTPS assay and L-glutamine and AMP-PNP are used, no CTP is formed but L-glutamine is hydrolyzed. It is also known that the reactions with free $\mathrm{NH}_{3}$ and L-glutamine are competitive; if L-glutamine is absent, then free ammonia will use the ammonia site for CTP production.

Purification of CTPS from Chinese hamster cells is hampered because of the difficulty of obtaining a sufficient quantity of cells. However, when at least a partial purification of CTPS from Chinese hamster cells is obtained, we plan to focus on the roles played by each amino donor component in the various synergistic combinations. For example, with the synergistic combinations of L-glutamine plus $\mathrm{NH}_{4} \mathrm{HCO}_{3}$ or L-arginine we do not know if each component contributes an $-\mathrm{NH}_{2}$ group to UTP or whether one of the components acts only to 'facilitate' the $-\mathrm{NH}_{2}$ transfer by the other component. Our results indicate that when L-glutamine and $\mathrm{NH}_{4} \mathrm{HCO}_{3}$ were used as potential amino donors a small reduction (about 16\%) in CTP formation was observed when GTP was omitted from the assay mixture. Since GTP is an allosteric effector only when L-glutamine is the amino donor, the results could indicate that $\mathrm{NH}_{4} \mathrm{HCO}_{3}$ may be the major donor. Still unexplained, however, is the reason for the apparent synergism of the potential amino donors, since L-glutamine clearly enhances the production of CTP when in combination with $\mathrm{NH}_{4} \mathrm{HCO}_{3}$. The present understanding of the mechanism of CTPS does not indicate that a conformational change takes place when the amino donor, L-glutamine, forms a complex with a cysteine moiety of the enzyme. Although the glutamine reaction and the ammonia reaction are apparently competitive, we are unclear whether the amino group of L-glutamine and ammonia occupy exactly the same site. Perhaps the synergism we observe involves small changes in conformation such that one or both potential amino donors achieves a 'better fit' at the ammonia site.

When L-glutamine and L-arginine were used as potential amino donors we found a moderate reduction (about $51 \%$ ) in CTP formation if GTP was omitted from the assay mixture. This could suggest that both L-glutamine and L-arginine are contributing about equally as amino donors. Again unexplained is the apparent synergism between both potential donors.

The combination of L-glutamine and potassium phosphate resulting in the conversion of UTP to CTP may be a different type of synergism than that between L-glutamine and $\mathrm{NH}_{4} \mathrm{HCO}_{3}$ or L-arginine. Clearly, potassium phosphate does not have an a mino group to donate, unlike $\mathrm{NH}_{4} \mathrm{HCO}_{3}$ or L-arginine. The only time a phosphate group is involved in the actual mechanism is the addition of phosphate derived from ATP to the UTP adduct that has just received the amino moiety. The phosphate group forms a bond at position number 4 of the pyrimidine ring of the UTP adduct, replacing an $-\mathrm{OH}$ group at the same position; this phosphate group is then cleaved, leaving only an $-\mathrm{NH}$ group bound at position number 4 , which is the product CTP. Our result may indicate that potassium phosphate first reacts with UTP to add the phosphate group to ring position number 4 , resulting in both a 
phosphate group and an -OH group at this position. This UTP adduct may then be more receptive to the addition of the amino group from L-glutamine to position 4, replacing the $-\mathrm{OH}$ group. This new adduct would then eliminate the phosphate to yield CTP. A possible experiment would be to use the ATP analog AMP-PNP in a reaction mixture containing both L-glutamine and potassium phosphate. CTP production might occur if the potassium phosphate in the assay mixture could replace the phosphate group normally transferred from ATP to the UTP adduct.

Future experiments to clarify the question of amino donor(s) could use a stable isotope such as ${ }^{15} \mathrm{~N}$ in one of the potential amino donors. For exa mple, either L-gluta mine or $\mathrm{NH}_{4} \mathrm{HCO}_{3}$ could have ${ }^{15} \mathrm{~N}$ in the potential donor group while the other compound would have ${ }^{14} \mathrm{~N}$ in its donor group. The CTP produced in such an assay could be collected and analyzed to determine if the amino group of CTP contained only ${ }^{15} \mathrm{~N}$, only ${ }^{14} \mathrm{~N}$, or a combination of both. The same procedure could be used for L-glutamine plus L-arginine. Such experiments would be definitive in demonstrating the true amino donor(s). An additional experiment which would be potentially useful would be to use radioactive L-arginine in synergistic combination with L-glutamine to assay CTPS. The reaction mix could be chromatographed using thin layer to separate the radioactive potential substrate, L-arginine, from possible radioactive products. In that way we would perhaps be able to gain some insight concerning the mechanism.

\section{Acknowledgements}

The work was supported by a grant GM 20608 from U.S. Public Health Service. The authors wish to thank Barbara Lamb for conducting the cell culture work, and Drs David Hewett- Emmett and Richard E. Tashian for reading the manuscript.

\section{References}

1. Koshland, D. E., Jr. and Levitzki, A., 1974. In: The Enzymes (Boyer, P. D., ed.), 3rd ed., Vol. 10, pp. 539-559, Academic Press, New York.

2. Kizaki, H., Williams, J. C., Morris, H. P. and Weber, G., 1980. Cancer Res. 40: 3921-3927.

3. Williams, J. C., Kizaki, H., Weiss, E. and Weber, G., 1978. Anal. Biochem. 91: 46-59.

4. Williams, J. C., Kizaki, H., Weber, G. and Morris, H. P., 1978. Nature 271: 71-73.

5. Genchev, D. D., 1973. Experientia 29: 789-790.

6. Savage, C. R. and Weinfeld, H., 1970. J. Biol. Chem 245 : 2529-2535.

7. Ikenaka, K., Fukushima, M., Nakamura, H., Okamoto, M., Shirasaka, T. and Fuji, S., 1981, Gann 72: 590-597.

8. Tzeng, D. Y., Sakiyama, S., Kizaki, H. and Weber, G., 1981. Life Sci. 28: 2537-2543.

9. Kizaki, H., Sakurada, T. and Weber, G., 1981. Biochim. Biophys. Acta 662; 48-54.

10. McPartland, R. P. and Weinfeld, H., 1979. J. Biol. Chem. 254: 11394-11398.

11. Robert de Saint Vincent, B. and Buttin, G., 1980. Biochim. Biophys. Acta 610: 352-359.

12. Long, C. and Koshland, D. E., Jr., 1978. In: Methods in Enzymology (Hoffee, P. A. and Jones, M. E., eds.), Vol. LI, pp. 79-83, Academic Press, New York.

13. Weinfeld, H., Savage, C. R., Jr. and McPartland, R. P., 1978. In: Methods in Enzymology (Hoffee, P. A. and Jones, M. E., eds.), Vol. LI, pp. 84-90, Academic Press, New York. 14. Brockman, R. W., Shaddix, S. C., Williams, M., Nelson, J. A., Rose, L. M. and Schabel, F. M., Jr., 1975. Ann. N.Y. Acad. Sci. 255: 501-521.

Received 4 October 1982; in revised form 15 November 1982 